V.4, N.1, 2020

DOI: $10.33947 / 2595-6264-V 4 N 1-4579$

\title{
REVITALIZAÇÃO DE CORPOS D’ÁGUA COM O USO DA BIORREMEDIAÇÃO
}

\author{
WATER BODIES REVITALIZATION USING BIOREMEDIATION
}

Luís Henrique Nunes de Souza1, Regina Oliveira Moraes Arruda²

\begin{abstract}
RESUMO
Água é a principal e essencial fonte de vida, indispensável para há vida como compreendemos, com está mentalidade de preservação da vida e das águas, métodos como biorremediação foram desenvolvidas para tratar algumas dessas fontes de vida ou tratar contaminações nas massas de água. O objetivo deste trabalho foi revitalizar a massa d'agua presente no interior do Zoológico Município de Guarulhos - SP, por meio de técnicas de Biorremediação. Para alcançar os objetivos propostos foi realizados métodos de biorremediação mediante, bioaumentação por meio de um misto de bactérias heterotróficas, bolores e leveduras e bioestimulação por equipamentos do laboratório. As coletas obedeceram aos parâmetros de preservação e transporte, estabelecidos pela Agência Nacional de Águas. Foram analisadas as variáveis; condutividade elétrica (CE), clorofila a (CL), coliformes termotolerantes (CF), demanda bioquímica de oxigênio (DBO), nitrogênio total (NT), oxigênio dissolvido (OD), pH, Fósforo total (PT), sólidos totais (ST), temperatura (T) e Turbidez (TU). Foram calculados o índice de qualidade das águas (IQA) e do índice do estado estrófico (IET). O tratamento foi feito por 7 dias na Incubadora a $30^{\circ} \mathrm{C} / 135 \mathrm{rpm}$. Dentre os métodos avaliados tanto a bioaumentação como a biorremediação com um produto comercial (composto por bactérias heterotróficas, bolores e leveduras, bactérias anaeróbicas facultativas) não apresentou efeito sobre a eutrofização e qualidade geral das águas do lago estudado, nas condições estudadas. Novos estudos com diferentes biorremediadores devem ser realizados a fim de solucionar o problema de lagos urbanos eutrofizados.
\end{abstract}

PALAVRAS-CHAVE: Eutrofização. Qualidade de água. Lago urbano. Microrganismos.

\begin{abstract}
Water is the main and essential source of life, indispensable for life as we understand it, with this mentality of preserving life and water, methods such as bioremediation have been developed to treat some of these sources of life or to treat contamination in water bodies. The aim of this work was to revitalize the water mass present inside the Guarulhos Municipality Zoo - SP, through Bioremediation techniques. To achieve the proposed objectives, bioremediation methods were carried out by means of bio-augmentation by means of a mixture of heterotrophic bacteria, molds and yeasts and biostimulation by laboratory equipment. The collections followed the preservation and transport parameters established by the National Water Agency. The variables were analyzed; electrical conductivity (CE), chlorophyll a (CL), thermotolerant coliforms (CF), biochemical oxygen demand (BOD), total nitrogen (NT), dissolved oxygen (OD), $p H$, total phosphorus (PT), total solids (ST), temperature (T) and Turbidity (TU). The water quality index (IQA) and the strophic state index (IET) were calculated. The treatment was done for 7 days in the incubator at $30^{\circ} \mathrm{C} / 135 \mathrm{rpm}$. Among the methods evaluated, both bio-augmentation and bioremediation with a commercial product (composed of heterotrophic bacteria, molds and yeasts, facultative anaerobic bacteria) had no effect on the eutrophication and general quality of the waters of the studied lake, under the conditions studied. New studies with different bioremediators should be carried out in order to solve the problem of eutrophic urban lakes.
\end{abstract}

KEYWORDS: Eutrophysation. Water quality. Urban lake. Microorganisms.

\footnotetext{
${ }^{1}$ Graduado em Farmácia, Universidade UNG, luis.souza@ung.br

${ }^{2}$ Docente do curso de Farmácia e do Mestrado em Análise Geoambiental, Universidade UNG, rarruda@prof.ung.br
} 


\section{INTRODUÇÃO}

Água é a principal e essencial fonte de vida, indispensável para há vida como compreendemos, no Brasil é supervisionada pela Agência Nacional de Águas (ANA), através de diversos bancos de dados como o Sistema Nacional de Informações sobre Recursos Hídricos (SNIRH) e metodologia de análises (ANA, 2019).

A World Health Organization (WHO, 2019 n.p.) define água como;

"essencial para a vida. A quantidade de água doce na terra é limitada e sua qualidade está sob pressão constante. Preservar a qualidade da água doce é importante para o abastecimento de água potável, produção de alimentos e uso recreativo da água. A qualidade da água pode ser comprometida pela presença de agentes infecciosos, produtos químicos tóxicos e riscos radiológicos"

Com este foco, pesquisas e projetos como o desenvolvido pela Empresa Brasileira de Pesquisa Agropecuária (Embrapa) junto a Universidade Federal de Santa Catarina - UFSC (UFSC, 2019), tem destaque na área de Preservação ambiental, por meio de um projeto de "tecnologias sociais para a gestão da água" visando ressaltar o uso consciente das bacias hidrográficas de sua região. Assim como pesquisas de, "Síntese e caracterização de nanopartículas de ferro-zero valente (nzvi) aplicadas ao tratamento de águas contaminadas com 4-clorofenol" (DUTRA, 2015).

O que acaba chamando mais a atenção são eventos como o dia da "Sobrecarga da terra" (WWF, 2019), que demonstram que com o passar dos anos utilizamos o planeta mais rápido do que o mesmo se regenera, em 2019, por meio do cálculo da Pegada Ecológica brasileira, é esperado que consumiremos 1,6 planetas em recursos, causados pela abordagem e condutas das pessoas.

Por conta disso, pesquisas que visam o cuidado com o meio ambiente, especificamente como esse trabalho que visa tratamento de água, se tornam essencial para proporcionar um cuidado melhor com a natureza. Para esse objetivo foi abortado a biorremediação, desenvolvida a partir da biotecnologia, que utiliza microrganismos de uma ou diversas classes, para degradar e proporcionar uma revitalização ambiental (DA SILVEIRA; TATTO; MANDAI, 2016, 2016).

\section{OBJETIVO}

Revitalizar o lago presente no interior do Zoológico de Guarulhos, Município de Guarulhos - SP, por meio de métodos de Biorremediação.

\section{REVISÃO BIBLIOGRÁFICA Biorremediação}

Considerando que a água em seu processo de sustentabilidade, tem como princípio os fundamentos ecológicos, da prevenção e da precaução, dos cuidados com os poluentes (CONAMA, 2005), tem como base;

\footnotetext{
"Impacto ambiental é qualquer alteração das propriedades físicas, químicas e biológicas do meio ambiente, causada por qualquer forma de matéria ou energia resultante das atividades humanas que, direta ou indireta, afetam: a saúde, a segurança e o bem-estar da população; as atividades sociais e econômicas; a biota; as condições estéticas e sanitárias do meio ambiente; a qualidade dos recursos ambientais" (BRASIL, 1986 p.1).
}

Biorremediação é um processo onde utilizam microrganismos (figura 1) a fim de reduzir ou eliminar poluentes e contaminantes, excretados na área (GAYLARDE; BELLINASO; MANFIO, 2005, DA SILVEIRA; TATTO; MANDAI, 2016). Utilizado como alternativa no tratamento de águas, como em casos de efluentes de industriais ou/e resíduos orgânicos, podem beneficiar na gestão ambiental em vez de técnicas físico-químicas ou químicas comumente utilizadas. Está é uma alternativa ecologicamente aceitável, onde seus princípios partem da biotecnologia com uso de microrganismo.

Pereira, Freitas, 2012, concluíram em sua pesquisa, que microrganismo tem a capacidade de reverter os impactos ambientais, assim como a importância dos microrganismos presentes "in loco", apresentam grande importância para os ecossistemas aquáticos, tendo a capacidade de revitalizar os impactos ambientais.

Diversas técnicas de biorremediação (figura 1), como por exemplo; Bioestimulação onde se utiliza mi- 
crorganismos presentes na própria amostra favorecendo sua atividade para degradação de resíduos ou por Bioaumentação, onde são introduzidos microrganismos específicos que já tenham uma predisposição a degradação dos resíduos (GAYLARDE; BELLINASO; MANFIO, 2005, 2005).

\section{Bioaumentação}

Este é um processo que utiliza microrganismos externos (ou seja, não naturais do local de estudo), com ou sem a adição de fatores físico-químicos e/ou químicos, visando que esses microrganismos, uma ou mais matrizes ou de mais de um classe, como; fungos, bactéria e bolores, naturais ou modificados (GAYLARDE; BELLINASO; MANFIO, 2005, 2005) realizem processos que consumam as toxinas ou substâncias que estejam em excesso no ambiente, potencialmente causando um prejuízo para o corpo hídrico (JONES, 2012).

\section{Bioestimulação}

A bioestimulação se caracteriza pela não adição de microrganismos externos ao corpo hídrico, seu foco é que os microrganismos naturais do campo de estudo com auxílio de aditivos físico-químicos e/ou químicos, realizem a restauração do ambiente, otimizando assim suas funcionalidades e capacidades naturais. Segundo Jones (2012), a principal desvantagem do método está relacionada a necessidade de disponibilidade dessas formas de vida no ambiente.

Figura 1 Técnicas de Biorremediação

Figure 1 Bioremediation techniques

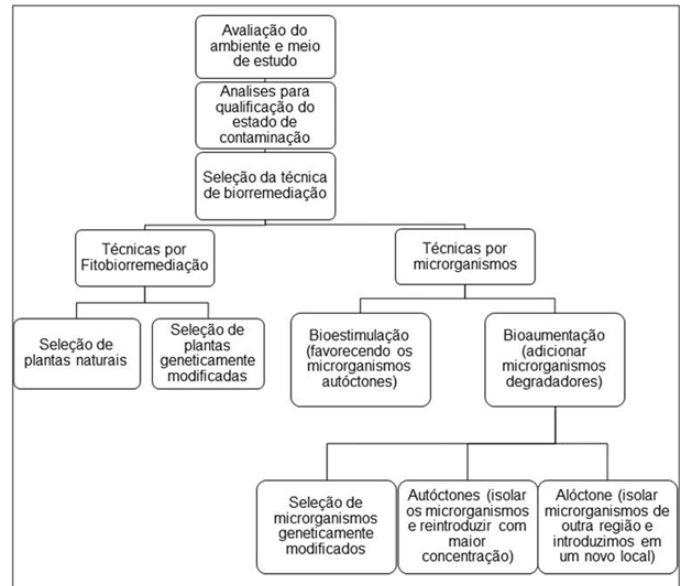

Fonte: Adaptado de Gaylarde; Bellinaso; Manfio, 2005.
Índice de qualidade das águas.

Em 1970 após estudos da "National Sanitation Foundation" dos Estados Unidos da América sobre o abastecimento de água, a CETESB produziu seus parâmetros através do desenvolvimento do Índice de qualidade das águas (IQA), para investigação do abastecimento de água pública. Entre as 35 variáveis iniciais da pesquisa, foram selecionados de 9 variáveis considerados mais enfáticos, temperatura, $\mathrm{pH}$, Oxigênio Dissolvido, condutividade elétrica, fósforo, nitrogênio, DBO, Eschericia coli, turbidez e sólidos totais (CETESB, 2017). O valor de IQA pode variar entre 0 a 100, (tabela 1).

Tabela 1 - Classificação dos resultados para IQA.

Table 1 - Classification of results for IQA.

\begin{tabular}{|l|l|}
\hline Nivel de qualidade & Pontuação \\
\hline Ótima & $79<\mathrm{IQA} \leq 100$ \\
\hline Boa & $51<\mathrm{IQA} \leq 79$ \\
\hline Regular & $36<\mathrm{IQA} \leq 51$ \\
\hline Ruim & $19<\mathrm{IQA} \leq 36$ \\
\hline Péssima & $\mathrm{IQA} \leq 19$ \\
\hline
\end{tabular}

Fonte: Tabela adaptada do Apêndice D - Índices de Qualidade das Águas (CETESB, 2017).

\section{Índice do estado trófico}

O índice do estado trófico (IET), usado para classificar os diferentes níveis de qualidade do enriquecimento por nutrientes presentes na água ou o nível trófico (confirme tabela 2 , e suas classes) assim por se dizer, que está diretamente relacionado ao crescimento de plantas aquáticas e Fitoplâncton (ANA, 2019).

Tabela 2 - Categorias do Estado Trófico da água

Table 2 - Categories of the Trophic State of water

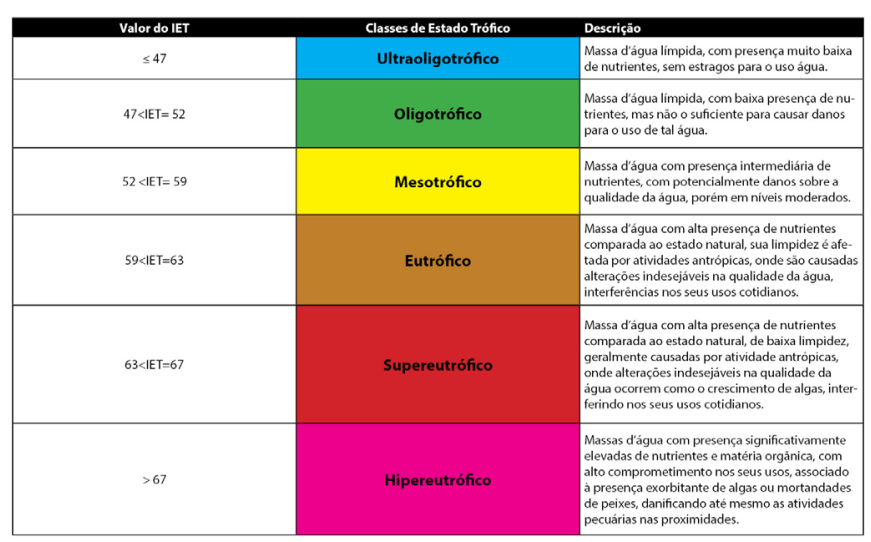

Fonte: adaptado do site da Agência Nacional de Águas 
(ANA, 2019).

Para realização dos métodos para os cálculos de IET (LAMPARELLI, 2004), através das análises de fósforo total mencionado no IQA e das análises de Clorofila a, utilizou-se as equações de 1 a 5, dependendo do corpo hídrico ser lêndico ou lótico.

$(1)$

(2)

Rios (lótico)

- IET $(\mathrm{Cl})=10 x(6-((-0,7-0,6 x(\ln \mathrm{CI})) / \ln 2))-20$

- IET $(\mathrm{PT})=10 x(6-((0,42-0,36 x(\operatorname{In} \mathrm{PT})) / \ln 2))-20$

Reservatórios (lêndico)

- IET $(\mathrm{Cl})=10 x(6-((0,92-0,34 x(\ln \mathrm{Cl})) / / \mathrm{In} 2))(3)$

- IET $(\mathrm{PT})=10 x(6-((1,77-0,42 x(\operatorname{In} \mathrm{PT})) / \mathrm{In} 2))(4)$

Onde: $\ln =$ logarítmico natural

$\mathrm{Cl}=$ clorofila $a(\mu \mathrm{g} / \mathrm{L})$

$\mathrm{PT}=$ fósforo $(\mathrm{mg} / \mathrm{L})$

Com os valores obtidos é realizado a seguinte fórmula final, para a conclusão do valor de IET:

$$
\text { IET = [IET (PT) + IET (CI)] / } 2
$$

\section{Legislação}

De acordo com a legislação n¹2.651/2012 (BRASIL, 2012), a Área de Preservação Permanente - APP corresponde a uma área protegida, coberta ou não por vegetação nativa, cuja função ambiental é a de preservar os recursos hídricos, a paisagem, a estabilidade geológica e a biodiversidade, facilitar o fluxo gênico de fauna e flora, proteger o solo e assegurar o bem-estar das populações humanas.

Segundo a resolução No 420/2009: "Remediação: uma das ações de intervenção para reabilitação de área contaminada, que consiste em aplicação de técnicas, visando a remoção, contenção ou redução das concentrações de contaminantes." (BRASIL, 2009 p. 4).

Para veracidade dos resultados de E.coli ao tratar-se de uma bactéria fecal ela é encontrada em abundância em córregos, esgotos, regiões com baixo índice de saneamento básico, tratamento e capitação de esgoto. Legislação de referência CONAMA 274/2000 (CONAMA, 2000). A tabela 3, aponta os padrões para as variáveis estabelecidos pela Resolução CONAMA 375/2005, para classe 3 (referente ao corpo hídrico pesquisado aqui).

Tabela 3 - Limites para as análises segundo a CONAMA 357/2005 para classe 3 .

Table 3 - Limits for the analysis according to CONAMA 357/2005 for class 3.

\begin{tabular}{|c|c|}
\hline \multicolumn{1}{|c|}{ Parâmetro } & Padrăo \\
\hline DBO & $\leq 10 \mathrm{mg} . \mathrm{L}-1 \mathrm{O} 2$ \\
\hline Oxigênio dissolvido & $>4 \mathrm{mg} . \mathrm{L}-1 \mathrm{O} 2$ \\
\hline Turbidez & $\leq 100 \mathrm{NTU}$ \\
\hline $\mathrm{pH}$ & $\mathrm{Entre} 6,0 \mathrm{a} 9,0$ \\
\hline Sólidos totais & $<500 \mathrm{mg} . \mathrm{L}-1$ \\
\hline Fósforo total & $<0,075 \mathrm{mg} . \mathrm{L}-1$ \\
\hline & $<13,3 \mathrm{mg} . \mathrm{L}-1 \mathrm{~N}, \mathrm{para} \mathrm{pH} \leq 7,5$ \\
Nitrogênio total & $<5,6 \mathrm{mg} \mathrm{L}-1 \mathrm{~N}$, para $7,5<\mathrm{pH} \leq 8,0$ \\
& $<2,2 \mathrm{mg} . \mathrm{L}-1 \mathrm{~N}$, para $8,0<\mathrm{pH} \leq 8,5$ \\
& $<1,0 \mathrm{mg} . \mathrm{L}-1 \mathrm{~N}$, para $\mathrm{pH}>8,5$ \\
\hline Coliformes Termotolerantes & $<2500 \mathrm{UFC} / 100 \mathrm{~mL}$ \\
\hline Clorofila a & $<60 \mathrm{\mu g} / \mathrm{L}$ \\
\hline
\end{tabular}

Fonte: Dados obtidos e adaptados a partir do CONAMA, 2005

\section{METODOLOGIA}

A pesquisa consistiu inicialmente de uma análise previa do Zoológico Município de Guarulhos - SP e seus lagos urbanos, para que assim fosse selecionado o ponto de amostra. O lago selecionado, é último dentro dos limites do Zoológico Municipal de Guarulhos - SP, antes se se tornar um córrego de livre acesso urbano.

As coletas aconteceram sempre no ponto indicado no mapa (figura 4), todas durante o inverno e sendo realizado em duplicata nas duas fases, no teste de concentração e teste de biorremediação. Em todas as coletas, os procedimentos de armazenagem e preparo, assim como os frascos utilizados e todo manuseio das amostras, seguirão as normas estabelecidas pela Agência Nacional de Águas (BRANDÃO, 2011).

Para a análise de E.coli foi realizado o método de membranas filtrantes. Onde é coletado $100 \mathrm{ml}$ de cada amostra e filtrada sobre a membrana filtrante, na bomba a vácuo, após isso foi plaqueado no Agar HiCrome UTI modificado, após a técnica as amostras foram incubadas a $37^{\circ} \mathrm{C}$, durante 24 horas, para exceção da contagem das colônias.

O procedimento segue de forma geral conforme o fluxograma (figura 2). 
Figura 2 - Fluxograma resumido da metodologia utilizada.

Figure 2 - Summary flowchart of the methodology used

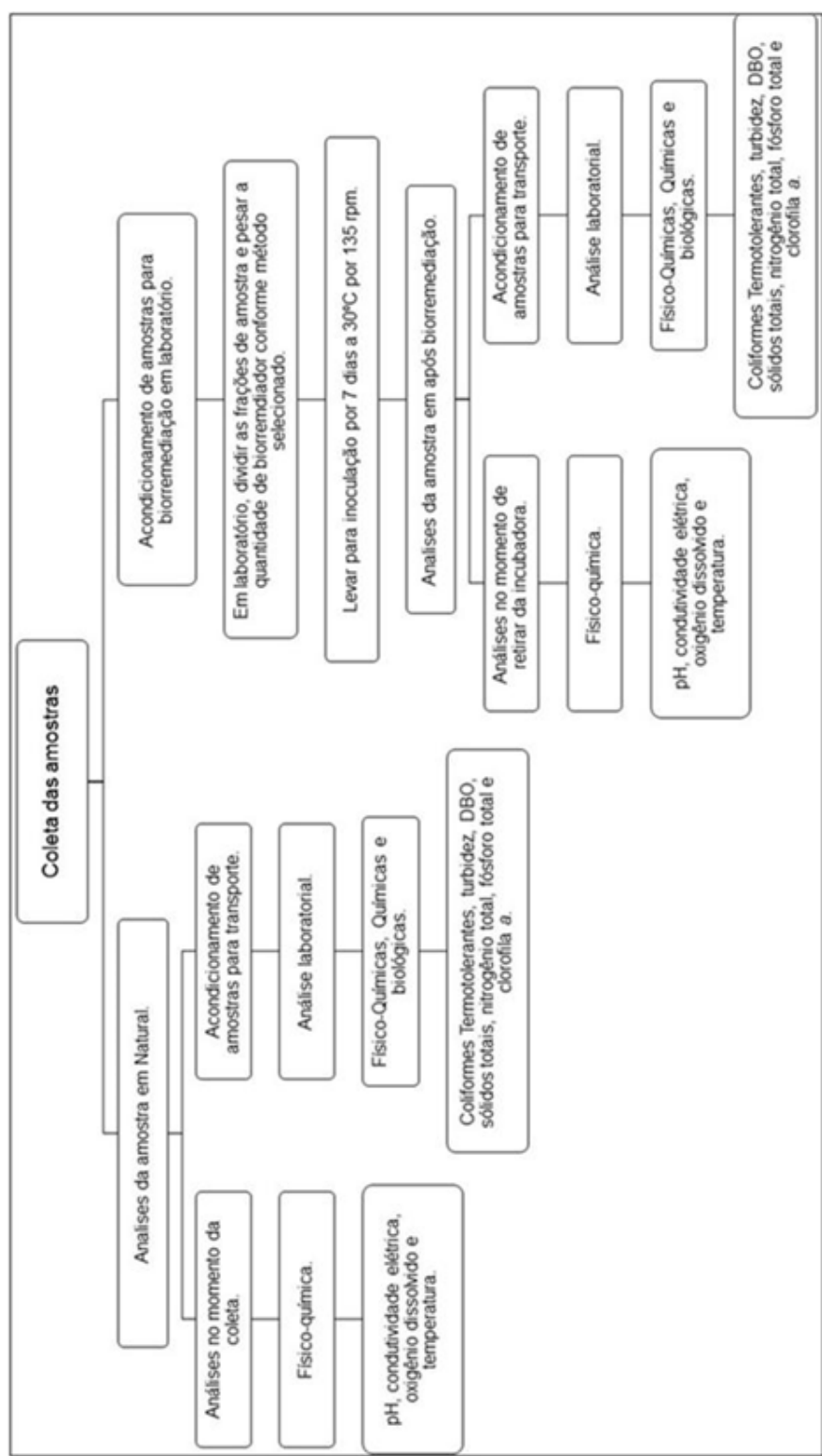

Fonte: Confeccionado pelo autor

\section{Área de estudo}

O local de estudo escolhido foi o Zoológico Municipal de Guarulhos - SP, que tem como objetivo apresentar e orientar a população sobre os cuidados da fauna e flora do município de Guarulhos - SP (GUARULHOS, 2019), foi utilizado como amostra o lago nomeado como $6^{\circ}$ lago, conforme figura 3 .
Figura 3 - Ponto de coleta

Figure 3 - Sampling point

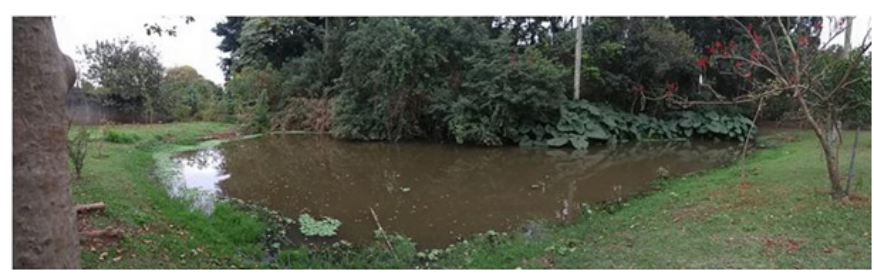

Fonte: Foto tirada pelo autor

Segundo o decreto no 10.755, de 22 de novembro de 1977 (SÃO PAULO, 1977), o Córrego Ana Rita (23²6'36.99"S 46³3'17.61"O, localização obtida pelo Google Earth Pro, figura 4), que pertence ao Sub-bacia do Rio Cabuçu de Cima.

Figura 4 - Mapa do Zoológico Municipal de GuaruIhos - SP, destacando o ponto de coleta (em amarelo)

Figure 4 - Map of the Municipal Zoo of Guarulhos - SP, highlighting the sampling point (in yellow)

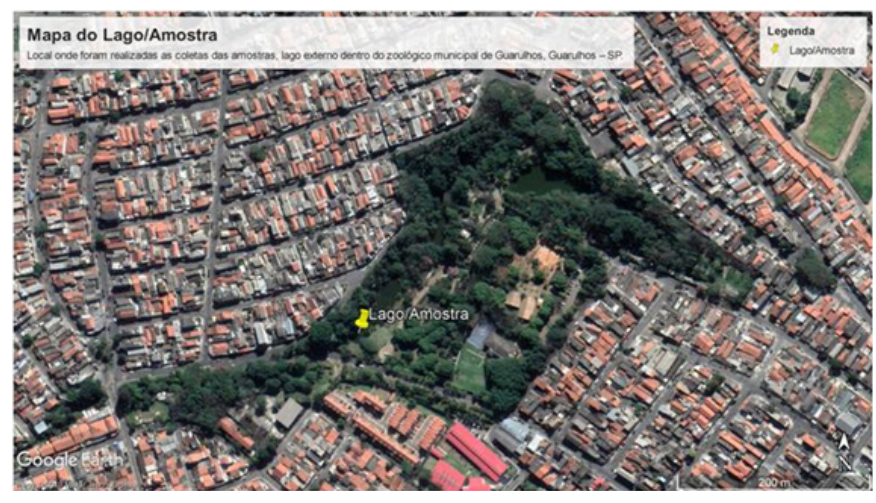

Fonte - Mapa do Fonte: Imagem gerada pelo Google Earth Pro, confeccionada pelo autor de coleta e Zoológico de Guarulhos

\section{Biorremediador}

Para realização dos ensaios o biorremediador (comercial) utilizado tem as seguintes características; Bactérias heterotróficas $6,17 \times 105$, UFC/25g bolores e leveduras 9,00n105 UFC/25g e bactérias anaeróbicas facultativas $1,00 \times 105$ UFC/25g.

\section{Teste de concentração do biorremediador}

Neste teste de concentração do biorremediador em laboratório demonstrado no quadro 1 , há amostra "Na- 
tural" representa as condições da amostra do mesmo dia da coleta, as demais amostras tiveram a adição do biorremediador representada em $\mathrm{g} / \mathrm{L}$ :

Quadro 1 Descrição do método e concentração usada de biorremediador

Table 1 Description of the method and concentration used of the bioremediator

\begin{tabular}{|c|c|c|}
\hline Concentraçāo do biorremediador & Técnica de Biorremediaçāo & Condiçōes do teste \\
\hline Natural & 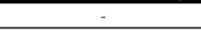 & Condiçōes do dia de coleta \\
\hline $0,50 \mathrm{~g} / \mathrm{L}$ & \multirow{4}{*}{ Bioaumentaçăo } & \multirow{5}{*}{7 dias na Incubadora a $30^{\circ} \mathrm{C} / 135 \mathrm{rpm}$} \\
\hline $0,25 \mathrm{~g} / \mathrm{L}$ & & \\
\hline $0,10 \mathrm{~g} / \mathrm{L}$ & & \\
\hline $0,05 \mathrm{~g} / \mathrm{L}$ & & \\
\hline $0,00 \mathrm{~g} / \mathrm{L}$ & Bioestimulação & \\
\hline
\end{tabular}

Para esse teste foram realizadas as seguintes análises: turbidez (TU) (Turbidímetro Quimis Q279P), fósforo total (PT) e nitrogênio total (NT) segundo Standard Methods for examinations of Water and Wastewater (APHA, 2012).

\section{Teste de Biorremediação.}

No campo, as análises das águas foram feitas através de instrumentos analíticos devidamente calibrados e com medições em triplicata para os seguintes parâmetros físico-químicos: temperatura $(\mathrm{T}), \mathrm{pH}$, condutividade (CE) e oxigênio dissolvido (OD), medidos todos pelo Medidor Multiparâmetro à prova d'agua - AK87.

No laboratório foram realizadas as análises das variáveis de turbidez (TU) (Turbidímetro Quimis Q279P), fósforo total $(\mathrm{PT})$, nitrogênio total (NT), Sólidos totais (ST) e Escherichia coli (E. coli posteriormente corrigidas para CF) segundo Standard Methods for examinations of Water and Wastewater (APHA, 2012). Para clorofila a (CL) metodologia adaptada de WETZEL \& LIKENS (1991) e a demanda bioquímica de oxigênio (DBO) por meio dos analisadores eletrônicos de DBO via método manométrico (DBO Sensor VELP).

\section{RESULTADOS E DISCUSSÃO}

Resultados do teste de concentração do biorremediador.

Este tópico se refere somente as análises do teste para escolha da concentração, onde foram obtidos os seguintes resultados no quadro 2 ;
Quadro 2 Resultados do teste de concentração do biorremediador.

Table 2 Results of the bioremediator concentration test.

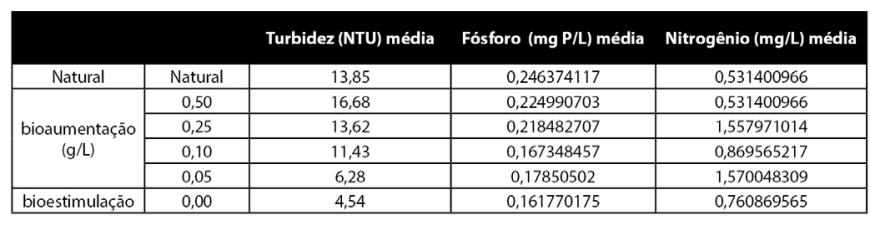

A amostra que utiliza $0,10 \mathrm{~g} / \mathrm{L}$ da solução de biorremediação apresenta o melhor estado de tratamento do nitrogênio e fósforo, com valores próximos a amostra sem aditivo $(0,00 \mathrm{~g} / \mathrm{L} /)$, por conta destes dados, foi realizado a segunda fase (IET e IQA).

\section{Resultados do teste de Biorremediação.}

Após a seleção da concentração do biorremediador, foi realizado o teste para verificar como a amostra de comporta em um teste de tratamento utilizando as duas técnicas, conforme demonstrado no quadro $3 \mathrm{e}$ seus resultados calculados para o IQA e IET;

Quadro 3 Resultado das análises e dos cálculos de IQA e IET.

Table 3 Result of IQA and IET analyzes and calculations

\begin{tabular}{|c|c|c|c|}
\hline & \multicolumn{3}{|c|}{ Amostras } \\
\hline & Natural & Bioestimulação & $\begin{array}{c}\text { Bioaumentação } \\
0,10 \mathrm{~g} / \mathrm{L}\end{array}$ \\
\hline $\mathrm{CE}(\mu \mathrm{S} / \mathrm{cm})$ & 148,3 & 158,7 & 186,6 \\
\hline $\mathrm{CL}(\mu \mathrm{g} / \mathrm{L})$ & 26,3 & 3,2 & 35,5 \\
\hline CF (UFC/100ml) & 969 & 125 & 210 \\
\hline $\mathrm{DBO}(\mathrm{mg} / \mathrm{L})$ & 3,80 & 49,00 & 50,80 \\
\hline NT (mg/L) & $<0,50$ & $<0,50$ & $<0,50$ \\
\hline$O D$ (mg/L) & 3,1 & 7,4 & 6,5 \\
\hline $\mathrm{pH}$ & 7,60 & 8,09 & 8,20 \\
\hline PT (mg/L) & 0,10 & 0,10 & 0,20 \\
\hline $\mathrm{ST}(\mathrm{mg} / \mathrm{L})$ & 22,60 & 18,70 & 18,20 \\
\hline Temp $\left({ }^{\circ} \mathrm{C}\right)$ & 20,30 & 20,30 & 20,30 \\
\hline TU (NTU) & 15,20 & 10,80 & 11,00 \\
\hline \multicolumn{4}{|c|}{ IQA } \\
\hline IQA & 55 & 53 & 49 \\
\hline \multicolumn{4}{|c|}{ IET } \\
\hline ITE* CL $(\mu \mathrm{g} / \mathrm{L})$ & 26,3 & 3,2 & 35,5 \\
\hline IET ${ }^{* *} \mathrm{CL}\left(\mu \mathrm{g} \cdot \mathrm{L}^{-1}\right)$ & 62,76 & 52,43 & 64,24 \\
\hline IET** PT (mgP/L) & 20,51 & 20,01 & 24,71 \\
\hline IE* média & 41,64 & 36,22 & 44,48 \\
\hline
\end{tabular}

${ }^{*}$ Com base no valor isolado de clorofila **LAMPARELLI, 2004

Com relação aos valores do Índice de Estado Trófico, nenhum dos tratamentos teve ação direta na quali- 
dade das águas, pois a quantidade baixa de fósforo se contrapôs a quantidade de clorofila na água, equilibrando os valores e no geral essas águas não estão eutrofizadas.

Pimenta (2012) usou a Chlorella vulgaris como biorremediador para amostras de água para remoção de amónia, e também a técnica da bioaumentação foi mais eficiente.

Analisando com mais detalhes IQA, temos as figuras 5,6 e 7, o OD gerou o principal impacto na amostra natural, e o DBO quando se fez bioaumentação e biorremediação, que pode ser explicada pois uma maior concentração de microrganismos na água vai gerar um maior DBO, impactando no valor do IQA.

Figura 5 Cálculo do IQA para amostra sem tratamento.

Figure 5 Calculation of IQA for untreated sample

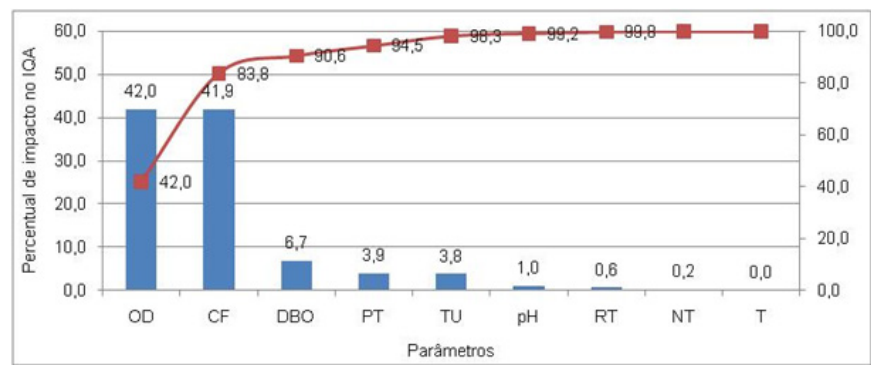

Fonte: Próprio autor

Figura 6 Cálculo do IQA para amostra tratada com Bioestimulação

Figure 6 Calculation of IQA for sample treated with Biostimulation

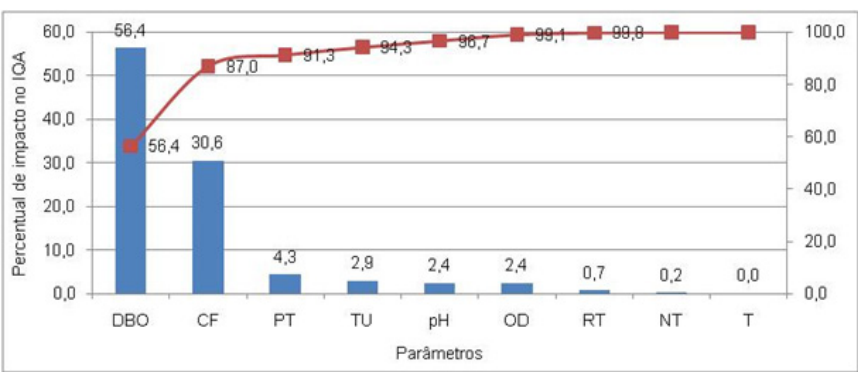

Fonte: Próprio autor
Figura 7 Cálculo do IQA para amostra Biorremediador/Bioaumentação $(0,10 \mathrm{~g} / \mathrm{L})$

Figure 7 Calculation of IQA for Biorremediator / Bioincrease sample $(0.10 \mathrm{~g} / \mathrm{L})$

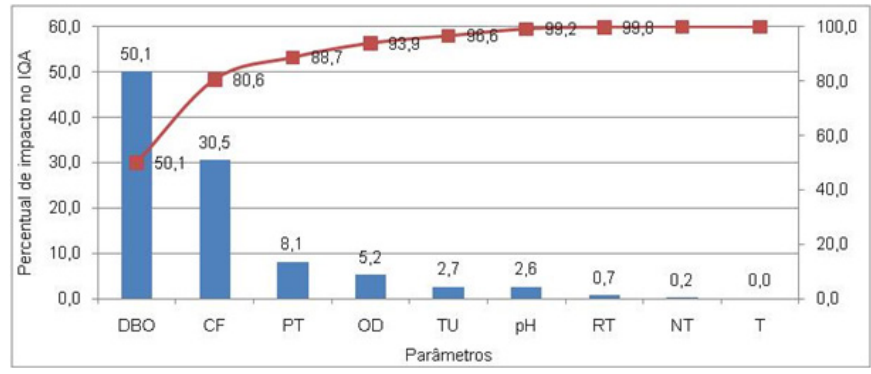

Fonte: Próprio autor

$\mathrm{Na}$ amostra natural, o parâmetro que mais pesou no IQA foi o valor de OD, pois a medição foi feita no próprio lago, que é um corpo lêntico, porém com pouco movimento. Mas nas amostras de bioestimulação e bioaumentação esse fator não foi importante pois o ensaio foi feito sob agitação artificial (135 rpm).

Mas, nas amostras de bioestimulação e bioaumentação no parâmetro que mais impactou o IQA foi a DBO, pois tanto um como outro estimularam o crescimento microbiano, demandando de mais oxigênio do corpo hídrico.

Em todas as amostras o parâmetro coliforme fecal foi o que teve também impacto nos valores de IQA, essas águas pertencem a um Zoológico é o último lago de uma sequência de 6 lagos, três deles estão nos viveiros e são usados pelos animais, por isso a alta presença desses microrganismos.

Böckler, Pereira, Simm (2016) utilizaram fungos (Stropharia rugoso-annulata) imobilizado em cavacos de madeira como biorremediador em águas contaminadas com coliformes fecais e obtiveram bons resultados, retirando cerca de $80 \%$ da contaminação.

Carvalho (2017) avaliou a capacidade de biorremediação do fungo aquático Articulospora tetracladia para remoção de concentrações elevadas de nutrientes na água, e obteve bons resultados, o fungo foi imobilizado em folhas de carvalho e plátano.

Aplicar a bioestimulação em um lago pode ser consideravelmente complicado, já que depende de alguns equipamentos. A bioaumentação é a técnica mais adequada, mas seria necessário um novo teste dessa vez in sito para confrontar se os fatores ambientais do lago 
teriam o mesmo resultado.

\section{CONCLUSÃO}

Neste trabalho apresentou-se a possibilidade de revitalização de um lago urbano, aqui representado pelas águas do lago presente no interior do Zoológico de Guarulhos, Município de Guarulhos - SP, por meio de métodos de Biorremediação.

Para a pesquisa, foram coletadas as amostras de água do lago, e os testes de biorremediação foram feitos em laboratório. Dentre os métodos avaliados tanto a bioaumentação como a biorremediação com um produto comercial (composto por bactérias heterotróficas, bolores e leveduras, bactérias anaeróbicas facultativas) não apresentou efeito sobre a eutrofização e qualidade geral das águas do lago estudado.

Novos estudos com diferentes biorremediadores devem ser realizados a fim de solucionar o problema de lagos eutrofizados.

\section{REFERÊNCIAS}

ANA - Agência Nacional de Águas. Portal da Qualidade das Águas Disponível em: http://portalpnqa.ana.gov.br. Acesso em: 06 maio de 2019.

AMERICAN Public Health Association (APHA); American Water Works Association (AWWA); Water Environment Federation (WEF)Standard methods for the examination of water and wastewater. 22. ed. Washington, D.C.: APHA/AWWA/WEF, 2012.

BÖCKLER, T. P.; PEREIRA, K. K.; SIMM, K. C. B. Utilização de fungos na biorremediação de águas contaminadas por coliformes fecais. Revista Thêma et Scientia, v. 6, n. 2E, p. 282-296, 2016.

BRANDÃO, C. J. et al. Guia nacional de coleta e preservação de amostras: água, sedimento, comunidades aquáticas e efluentes líquidos. São Paulo: CETESB, 2011. Disponível em: http://arquivos.ana.gov.br/institucional/sge/CEDOC/Catalogo/2012/GuiaNacionalDeColeta.pdf. Acesso em: 04 maio 2019.

BRASIL. Lei no 12.651, de 25 de maio de 2012, Dispõe sobre a proteção da vegetação nativa; altera as Leis nos
6.938, de 31 de agosto de 1981, 9.393, de 19 de dezembro de 1996, e 11.428, de 22 de dezembro de 2006; revoga as Leis nos 4.771, de 15 de setembro de 1965, e 7.754 , de 14 de abril de 1989, e a Medida Provisória no 2.166-67, de 24 de agosto de 2001; e dá outras providências. Diário Oficial [da] Republica do Federativa do Brasil, Poder Executivo, Brasília, DF, 25 de maio de 2012 Disponível em: http://www.planalto.gov.br/ ccivil_03/_ato2011-2014/2012/lei//12651.htm. Acesso em: 20 dez. 2017.

BRASIL, Ministério do Meia Ambiente, Resolução No 420, DE 28 DE DEZEMBRO DE 2009, Dispõe sobre critérios e valores orientadores de qualidade do solo quanto à presença de substâncias químicas e estabelece diretrizes para o gerenciamento ambiental de áreas contaminadas por essas substâncias em decorrência de atividades antrópicas. Publicado no Diário Oficial da União n 249, de 30/12/2009, págs. 81-84 Disponível em : http://www2.mma.gov.br/port/conama/legiabre. cfm?codlegi=620. Acesso em: 23 maio 2019.

BRASIL, Ministério do Meio Ambiente, Resolução CONAMA n 001 , de 23 de janeiro de 1986, Estabelecerem as definições, as responsabilidades, os critérios básicos e as diretrizes gerais para uso e implementação da Avaliação de Impacto Ambiental como um dos instrumentos da Política Nacional do Meio Ambiente Diário Oficial da União em 17 de fevereiro de 1986 Disponível em: http:// www.mma.gov.br/port/conama/res/res86/res0186.html. Acesso em: 20 abr. 2019.

CARVALHO, A. R. S. L. Avaliação da qualidade ecológica de um troço eutrofizado e potencial dos fungos para a biorremediação. 2017. Dissertação (Mestrado em Ecologia) - Universidade do Minho, 2017.

CETESB (São Paulo) - Apêndice D - Índices de Qualidade das Águas 2017 Disponível em: https://cetesb. sp.gov.br/aguas-interiores/publicacoes-e-relatorios/. Acesso em: 11 mar. 2019.

CONAMA. Resolução N 274/2000 - "Revisa os critérios de Balneabilidade em Águas Brasileiras" - Data da legislação: 29 de novembro de 2000 - Publicação no Diário Oficial da União $n^{\circ}$ 018, de 08/01/2001, págs. 70-71, Disponível em: http://www2.mma.gov.br/port/conama/le- 
giabre.cfm?codlegi=272. Acesso em: 26 nov. 2019.

CONAMA. Resolução N 357/2005 - "Dispõe sobre a classificação dos corpos de água e diretrizes ambientais para o seu enquadramento, bem como estabelece as condições e padrões de lançamento de efluentes, e dá outras providências." - Data da legislação: 17 de março de 2005 - Publicada no Diário Oficial da União $n^{\circ}$ 053, de 18/03/2005, págs. 58-63, Disponível em: http:// www2.mma.gov.br/port/conama/res/res05/res35705. pdf. Acesso em: 03 maio 2019.

SILVEIRA, L. R.; TATTO, J.; MANDAI. P. Biorremediação: considerações gerais e características do processo. Engenharia Ambiental: Pesquisa e Tecnologia, v. 13, n. 2, 2016.

DUTRA, M. C. Síntese e caracterização de nanopartículas de ferro-zero valente (NZVI) aplicadas ao tratamento de águas contaminadas com 4-clorofenol. 2015. 78 f. Dissertação (Pós-Graduação em Engenharia Química) - Universidade Federal de Santa Catarina, Florianópolis, 2015.

GAYLARDE, C. C.; BELLINASO, M. L.; MANFIO, G. P. Biorremediação. Biotecnologia Ciência \& Desenvolvimento, v. 34, p. 36-43, 2005. Disponível em: http:// www1.esb.ucp.pt/twt/olimpiadasbio07/MyFiles/MyAutoSiteFiles/Fontes/nformacao253906202/samorais/Biorremediacao.pdf Acesso em: 01 maio 2019.

PREFEITURA DE GUARULHOS. Zoológico Municipal de Guarulhos. Guarulhos: Prefeitura de Guarulhos, 2018. Disponível em: https://www.Guarulhos.sp.gov.br/ zoologico/index.html. Acesso em 06 maio 2019.

JONES, C. M. A. Bioaumentação pode ajudar os Sistemas de Tratamento de Efluentes. Rio de Janeiro: INOG - Instituto Nacional de Óleo e Gás/CNPq, FGEL - Faculdade de Geologia, UERJ - Universidade do Estado do Rio de Janeiro, 2012.

LAMPARELLI , M. C. Grau de trofia em corpos d'água do estado de São Paulo: avaliação dos métodos de monitoramento. 2004. 235 f. Tese (Doutorado de Ecologia) - Universidade de São Paulo, São Paulo, 2004.
PEREIRA, A. R. B.; FREITAS, D. A. F. Uso de micro-organismos para a biorremediação de ambientes impactados. Revista Eletrônica em Gestão, Educação e Tecnologia Ambiental, v. 6, n. 6, p. 995-1006, 2012.

PIMENTA, S. F. P. Comparação entre a biorremediação de água natural e água residual utilizando Chlorella vulgaris. 2012. Dissertação (Mestrado em Biologia e Gestão da Qualidade da Água) - Faculdade de Ciências da Universidade do Porto, 2012.

SÃO PAULO. decreto $\mathrm{n}^{\circ} 10.755$, de 22 de novembro de 1977, Dispõe sobre o enquadramento dos corpos de água receptores na classificação prevista no decreto $n^{\circ}$ 8.468, de 8 de setembro de 1976 e dá providência correlatas. Governo do estado de São Paulo, Poder Executivo, São Paulo, SP, 23 de novembro de 1977 Disponível em: https://www.al.sp.gov.br/repositorio/legislacao/ decreto/1977/decreto-10755-22.11.1977.html. Acesso em: 22 fev. 2019.

UFSC - Universidade federal de Santa Catarina. Projeto - tecnologias sociais para a gestão da água. Disponível em: http://tsga.ufsc.br/index.php/tsga/projeto. Acesso em: 18 out. 2019.

WETZEL, R. G.; LIKENS, G. E. Limnological Analyses. Springer-Verlag, 1991. $391 \mathrm{p}$.

WHO - World Health Organization - Organização Mundial da Saúde. Disponível em: https://www.who.int/topics/water/en/. Acesso em: 16 out. 2019.

WWF - World Wide Fund for Nature - Fundo Mundial para a Natureza. Disponível em: https://www.wwf.org. br/overshootday.cfm. 